\title{
A Quantitative and Qualitative Comparison of Fibrin Glue, Albumin, and Blood as Agents to Pretreat Porous Vascular Grafts
}

\author{
Steven R. Gundry, M.D. ${ }^{1}$ And Douglas M. Bẹhrendt, M.D. \\ Thoracic Unit, Hospital for Sick Children, Great Ormond Street, London, England, and the Division of \\ Thoracic Surgery, University of Michigan Medical Center, Ann Arbor, Michigan
}

Presented at the Annual Meeting of the Association for Academic Surgery, Washington, D.C., November 5-8, 1986

\begin{abstract}
Recent reports suggest that fibrin gluc can be used to seal porous vascular grafts prior to insertion, but this ability has not been quantitatively compared to existing methods. We compared blood loss from and handling characteristics of grafts pretreated with either fibrin glue (FG) (Tisseel), albumin autoclaving (AA), or blood preclotting (BP). Five 6-cm segments of 6-mm internal diameter grafts, both knitted and woven double velour Dacron were treated in each group (30 specimens). Human blood was forced through the BP group until clotted; AA segments were soaked in $25 \%$ human albumin and autoclaved for $10 \mathrm{~min}$; FG segments were treated with a topical application of Tisseel $(0.5$ $\mathrm{ml} / \mathrm{graft})$ followed by treatment with topical thrombin $+\mathrm{CACl}(0.5 \mathrm{ml} / \mathrm{graft})$. Graft ends were sealed and attached to a transducer/syringe pump mechanism which pumped heparinized human blood into the graft at $100 \mathrm{~mm} \mathrm{Hg}$ intraluminal pressure. All blood that leaked through the grafts over 2 min was collected and the amount was averaged for the five grafts in each group. Graft handling was characterized as either pliable or stiff. Blood pretreatment caused $21 \pm 2$ and $13 \pm 4 \mathrm{cc} / 2 \mathrm{~min}$ of leak in knitted and woven grafts, respectively. Albumin autoclaving resulted in $9 \pm 2$ and $1 \pm 0.5 \mathrm{cc}$ of leak $(P<0.01$ compared to blood), while fibrin glue produced $2 \pm 2$ and $0.4 \pm 0.5 \mathrm{cc}$ leaks $(P<0.01$ compared to blood). Both blood and fibrin glue produced soft pliable grafts, while albumin pretreatment resulted in stiff grafts. We conclude that fibrin glue or albumin is superior to blood for pretreatment of woven grafts in limiting blood loss, but that fibrin glue is superior to either albumin or blood in knitted grafts. Fibrin glue imparts superior handling characteristics. (1) 1987 Academic Press, Inc.
\end{abstract}

Primarily in Europe, fibrin glue has been used cxtensively since the early 1970 s to prevent bleeding from suture lines and to pretreat porous vascular grafts. Reports of its use are available as variable antecdoctal reports $[1,2,3]$ but fibrin glue has heretofore never been compared quantitatively or qualitatively to other methods of sealing porous vascular grafts.

This study was designed to determine the degree of sealing achieved by fibrin glue and to compare this result to that achieved by the traditional methods of pretreatment, blood preclotting, and albumin autoclaving. The amount of blood loss through and handling characteristics of both woven and knitted

\footnotetext{
${ }^{2}$ To whom reprint requests should be addressed at Division of Cardiothoracic Surgery, University of Maryland Hospital, 22 South Greene Street, Baltimore, MD 21201 .
}

double velour vascular grafts were evaluated for these three methods of pretreatment to determine the best available.

\section{METHODS}

Six-centimeter lengths of both knitted and woven double velour $6-\mathrm{mm}$ porous vascular grafts (Meadox) were obtained (30 total 6-cm specimens). Ten segments each ( 5 knitted, 5 woven) were treated with blood preclotting, albumin autoclaving, or fibrin glue sealing.

Blood preclotting was performed by forcing freshly obtained unheparinized blood through the vascular graft by using a catheter-tipped syringe while keeping the distal end sealed. Blood was continuously forced through the graft until clotting occurred; any intraluminal clot was squeezed out.

Albumin autoclaving was performed on another 10 segments. Segments were soaked 
TABLE 1

\begin{tabular}{lccc}
\hline & \multicolumn{3}{c}{ Blood leak (cc) } \\
\cline { 2 - 3 } & Knitted & Woven \\
\hline Blood (BP) & $21 \pm 2$ & 13 & \pm 4 \\
Albumin (AA) & $9 \pm 2^{*}$ & 1 & $\pm 0.5^{*}$ \\
Fibrin glue (FG) & $2 \pm 2^{*}$ & $0.4 \pm 0.5^{*}$ \\
\hline
\end{tabular}

${ }^{*} P<0.01$ compared to blood.

in $25 \%$ human albumin and then autoclaved for $10 \mathrm{~min}$.

A further 10 segments were treated with fibrin glue (Tisseel, Immuno, Ltd, Arctic House, Rye Lane, Dunton Green, Nr Sevenoaks, Kent, England). Graft segments were first covered with $0.5 \mathrm{cc}$ of Tisseel (human fibrin seal) and then covered with $0.5 \mathrm{cc}$ of topical thrombin mixed with calcium chloride. The fibrin glue-treated grafts were not allowed to dry.

Distal graft ends were then sealed. Proximal graft ends were tied around a Christmas-tree adaptor so that $5 \mathrm{~cm}$ of graft length was exposed. Heparinized blood was then forced into the graft at a pressure of 100 $\mathrm{mm} \mathrm{Hg}$ for a 2-min period. All blood leaking through the graft interstices was collected and measured.

Mean graft leakage was calculated for the five grafts in each group. Results are displayed in Table 1 as means \pm SD. Statistical significance was determined using one-way analysis of variance.

Handling characteristics were assessed by manually squeezing and molding the graft segments.

\section{RESULTS}

The amount of blood leaking through either knitted or woven grafts is displayed in Table 1. Blood preclotting was ineffective in preventing blood loss through vascular grafts, particularly the knitted variety. Albumin was an excellent agent for preventing blood loss through woven grafts, and while superior to blood, it still allowed for sizable leakage in knitted grafts. Fibrin glue produced nearly complete sealing of both knitted and woven grafts and was superior to blood in both types of grafts. It was also superior to albumin in pretreating knitted grafts.

Handling characteristics of both bloodand fibrin glue-treated grafts were excellent, both methods resulting in supple, easily handled grafts. Occasionally, blood-treated grafts were characterized as "sticky" while fibrin glue grafts were described as "slimy." Albumin-pretreated grafts were stiff and hard to mold, even seeming to "crack" with hard bending. Pieces of "cooked" albumin would flake off during handling.

\section{DISCUSSION}

Although experience with fibrin glue in some form is now well reported both in the United States and in Europe [1-7], this study is the first to compare its benefits quantitatively and qualitatively in preventing blood loss through porous vascular grafts with other traditional agents. This comparison is useful both to expand the indications for fibrin glue's use and to justify its use when other agents might be available.

While blood preclotting costs nothing, if significant blood loss occurs through the graft once in situ, the additional expenditure for blood replacement given the patient may quickly negate this cost advantage. When fibrin glue's use prevents or lessens the need for whole blood or packed cell replacement, then its small attendant risk of hepatitis transmission is nullified.

Fibrin glue has the additional advantage over blood in that blood preclotting cannot be performed in heparinized patients, a condition which occurs frequently in operations upon patients with ischemic limbs who have been placed on heparin therapy preoperatively. While the newer woven Dacron grafts have better preclotting ability and improved handling characteristics, many surgeons find distinct advantages in knittcd grafts, which will continue to require preclotting for the immediate future. 
Albumin preclotting has the distinct disadvantage of requiring a waiting period while the graft is cooked. Moreover, as is apparent to most people who have utilized this technique, the resultant graft is stiff and difficult to handle. The propensity of an albumin crust to flake off into the lumen of the graft and cause distal embolization is also of concern. Prosthetic valve function in composite grafts may also be adversely affected by albumin crusting.

At present, Tisseel, the form of fibrin glue utilized in this study, is not available in the United States. An equally effective method of making fibrin glue can be achieved by using cryoprecipitate in place of Tisseel. Cryoprecipitate is a rich source of fibrinogen, the active ingredient of Tisseel. In our general practice, a unit of cryoprecipitate is obtained thawed from the blood bank and placed in a 10-cc syringe. An ampoule of topical thrombin is similarly drawn up in a second syringe. Previously, we have mixed calcium chloride with the topical thrombin but we have eliminated it for the past 2 years and have noted no difference in effectiveness. The graft is covered with cryoprecipitate and rubbed in. This is followed by application of the topical thrombin which is similarly rubbed in. The graft should then be used soon after treatment; if drying occurs, leak rates rise. If grafts become dry, retreatment can be done in place. Indeed, if a leaky spot is noted on the grafts once in place, topical application of fibrin glue on the spot seals the leak.

\section{SUMMARY}

We conclude that fibrin glue or albumin is superior to blood preclotting for pretreatment of woven grafts in limiting blood loss, but that fibrin glue is superior to either albumin or blood in pretreating knitted grafts. Fibrin glue imparts superior handling characteristics over those achieved with albumin. We currently recommend that vascular grafts be treated with fibrin glue as the agent of choice to prevent blood loss through the graft in situ.

\section{REFERENCES}

1. Rousou, J. A., Engleman, R. M., and Breyer, R. H. Fibrin Glue: An effective hemostatic agent for nonsuturable intraoperative bleeding. Ann. Thorac. Surg. 38: 409, 1984.

2. Stark, J., and deLaval, M. Experience with Fibrin Seal (Tisseel) in operations for congenital heart defects. Ann. Thorac. Surg. 38: 411 , 1984.

3. Wolner, E. Fibrin gluing in cardiovascular surgery. Thorac. Cardiovasc. Surg. 30: 235, 1982.

4. Kalmar, P., Krebber, H.-J., Pokar, H., Tilsher, V. Bioadhesives in cardiac and vascular surgery. Thorac. Cardiovasc. Surg. 30: 230, 1982.

5. Koveker, G. Clinical application of fibrin glue in cardiovascular surgery. Thorac. Cardiovasc. Surg. 30: $228,1986$.

6. Meisner, H., Struck, E., Schmidt-Hakelmann, P., and Sebening, F. Fibrin seal application: Clinical experience. Thorac. Cardiovase. Surg. 30: 232, 1982.

7. Walterbusch, G., Haverich, A., and Borst, H. G. Clinical experience with Fibrin Glue for local bleeding control and sealing of vascular prostheses. Thorac. Cardiovasc. Surg. 30: 234, 1982. 